in vivo $34: 2561-2569(2020)$

doi:10.21873/invivo.12073

\title{
Calf Circumference as a Useful Predictor of Sarcopenia in Patients With Liver Diseases
}

\author{
HIROKI NISHIKAWA ${ }^{1,2^{*}}$, KAZUNORI YOH ${ }^{1 *}$, HIRAYUKI ENOMOTO ${ }^{1}$, YOSHINORI IWATA ${ }^{1}$, \\ YOSHIYUKI SAKAI ${ }^{1}$, KYOHEI KISHINO ${ }^{1}$, YOSHIHIRO SHIMONO ${ }^{1}$, NAOTO IKEDA ${ }^{1}$, \\ TOMOYUKI TAKASHIMA ${ }^{1}$, NOBUHIRO AIZAWA ${ }^{1}$, RYO TAKATA ${ }^{1}$, KUNIHIRO HASEGAWA ${ }^{1}$, \\ TAKASHI KORIYAMA ${ }^{1}$, YUKIHISA YURI ${ }^{1}$, TAKASHI NISHIMURA ${ }^{1}$, \\ SHUHEI NISHIGUCHI ${ }^{3}$ and HIROKO IIJIMA ${ }^{1}$ \\ ${ }^{1}$ Department of Internal Medicine, Division of Gastroenterology and Hepatology, \\ Hyogo College of Medicine, Nishinomiya, Japan; \\ ${ }^{2}$ Center for Clinical Research and Education, Hyogo College of Medicine, Nishinomiya, Japan; \\ ${ }^{3}$ Kano General Hospital, Osaka, Japan
}

\begin{abstract}
Background/Aim: To elucidate the influence of calf circumference $(C C)$ on sarcopenia in patients with chronic liver damages (CLDs, $n=525,255$ men). Patients and Methods: Anthropometry parameters including arm circumference, arm muscle circumference, CC, arm muscle area, triceps skinfold thickness, waist circumference and body mass index were measured. Patients with both grip strength (GS) decline and skeletal muscle index (SMI) decline were diagnosed as sarcopenic. Results: Liver cirrhosis was identified in 103 cases (40.4\%) in males and 87 cases (32.2\%) in females. Sarcopenia was identified in 23 male patients (9.0\%) and 38 female patients (14.1\%). CC had the strong positive correlation with SMI both in male $(r=0.79, p<0.0001)$ and female $(r=0.83$, $p<0.0001)$. Among the above mentioned 7 anthropometry parameters, CC had the highest area under the receiver operating characteristics curve (AUC) for sarcopenia both in males $(A U C=0.88)$ and females $(A U C=0.86)$. Conclusion: $C C$ can be helpful for predicting sarcopenia in CLDs.
\end{abstract}

In individuals with chronic liver damages (CLDs), metabolic or nutritional disorders including protein-energy-malnutrition

This article is freely accessible online.

*These Authors contributed equally to this work.

Correspondence to: Hiroki Nishikawa, MD, Ph.D., Department of Internal Medicine, Division of Gastroenterology and Hepatology, Hyogo College of Medicine, 1-1, Mukogawacho, Nishinomiyashi, Hyogo, 663-8501, Japan. Tel: +81 798456111, Fax: +81 798456608,e-mail: nishikawa_6392_0207@yahoo.co.jp

Key Words: Calf circumference, sarcopenia, chronic liver damage, screening tool, correlation. or muscle abnormalities are frequently observed, which can be related to falls, poor quality of life or poor prognosis (111). When the liver function deteriorates, the ability to detoxify harmful substances such as ammonia can decrease. Branched-chain amino acids (BCAAs) are often used in muscles to detoxify harmful substances in patients with decreased liver function (1). Sarcopenia, which is defined by decreased muscle mass and strength or decreased physical activity, can occur because the consumption of BCAAs prevents the synthesis of proteins required for muscle mass increase (1). Sarcopenia is one of the most common consequences observed in patients with liver cirrhosis (LC) $(1,8,12-18)$. Japanese CLD patients are gradually aging these days, which is also a crucial public health problem as aging is also closely linked to sarcopenia (19-21). To understand the association of sarcopenia with adverse outcomes, it is required to consider sarcopenia a systemic disorder (22-24). Clinical and research interest in sarcopenia is thus growing internationally.

Anthropometry is a convenient and non-invasive method to assess size and composition of the human body, and thus it is suitable for nutritional assessment in clinical settings (25-28). Arm circumference (AC), arm muscle circumference (AMC), calf circumference (CC) and arm muscle area (AMA), etc. are used to evaluate muscle mass, and body mass index (BMI), triceps skinfold thickness (TSF) and waist circumference (WC), etc. are used to evaluate fat mass (28). Of these parameters, measurement of $\mathrm{CC}$ is recommended in the revised Asian Working Group for Sarcopenia (AWGS) guidelines in order to facilitate earlier identification of sarcopenic individuals (29). The cutoff values of CC for sarcopenia in the revised AWGS guidelines are $34 \mathrm{~cm}$ in males and $33 \mathrm{~cm}$ in females (29). Kawakami, et al. have reported that CC was positively 


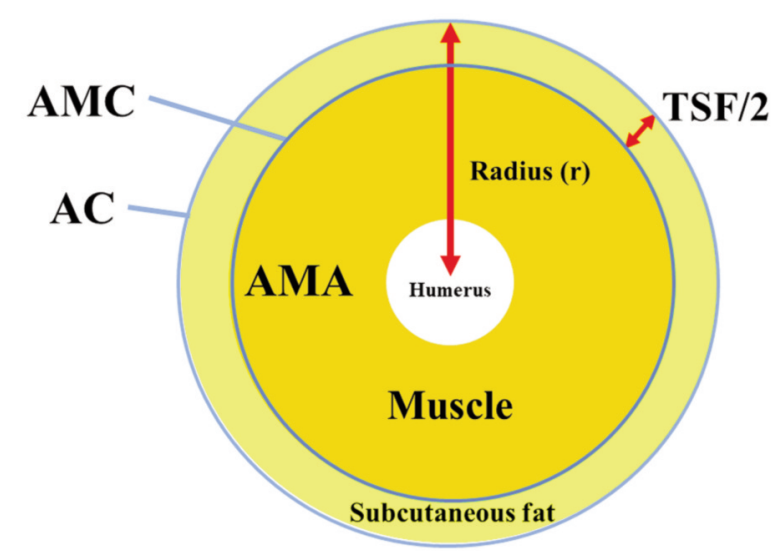

Figure 1. Diagram of AC, AMC, AMA and TSF. AC $(\mathrm{cm})=2 \pi r, A M C$ $(\mathrm{cm})=2 \pi(\mathrm{r}-T S F(\mathrm{~cm}) / 2)=A C-\pi T S F(\mathrm{~cm}), A M A=\pi(\mathrm{r}-T S F(\mathrm{~cm}) / 2)^{2}=(A M C$ $(\mathrm{cm}))^{2} / 4 \pi$.

correlated with SMI and could serve as a surrogate marker of muscle mass for diagnosing sarcopenia (30). When the questionnaire strength, assistance with walking, rising from chair, climbing stairs and falls (SARC-F) is combined with $\mathrm{CC}$, its sensitivity for identifying sarcopenia has been reported to be enhanced (31). Thus, clinical evidence regarding $\mathrm{CC}$ and sarcopenia have been accumulated. However, to the best of our knowledge, there have been few reports regarding the relationship between $\mathrm{CC}$ and sarcopenia in patients with CLDs $(32,33)$. The aim of the study was to elucidate the influence of CC on sarcopenia in patients with CLDs.

\section{Patients and Methods}

Patients. Five hundred and twenty-five CLD subjects evaluable for sarcopenia and anthropometry parameters consulted our hospital between April 2014 and January 2019, and they were participated in this study. LC was determined by liver biopsy, radiological findings (deformation of the liver surface, varices or splenomegaly, etc.), liver fibrosis markers and/or laboratory data (lower platelet count or prolonged prothrombin time) (34-37). Anthropometry parameters included AC $(\mathrm{cm}), \mathrm{TSF}(\mathrm{cm}), \mathrm{AMC}(\mathrm{cm}), \mathrm{CC}(\mathrm{cm})$, WC $(\mathrm{cm})$, AMA $\left(\mathrm{cm}^{2}\right)$ and BMI $\left(\mathrm{kg} / \mathrm{m}^{2}\right)$.

Grip strength (GS) was measured according to the current Japanese Society of Hepatology (JSH) guidelines, and the definition of decreased GS was: GS $<26 \mathrm{~kg}$ for males and $<18 \mathrm{~kg}$ for females (19). Skeletal muscle index (SMI) was tested using bioimpedance analysis (BIA) as described previously (38). The definition of SMI decline was: SMI $<7.0 \mathrm{~kg} / \mathrm{m}^{2}$ in males and $\mathrm{SMI}<5.7 \mathrm{~kg} / \mathrm{m}^{2}$ in females referring to the guidelines (19). Patients with both GS decline and SMI decline were diagnosed as sarcopenic (19). Because of the intrinsic limitations of BIA, which are hampered by ascites, patients with severe ascites were excluded from this study. We retrospectively examined the association of anthropometry parameters with sarcopenia in CLD patients. The institutional
Table I. Patient demographics.

\begin{tabular}{|c|c|c|c|}
\hline & Male $(n=255)$ & Female $(n=270)$ & $p$-Value \\
\hline Age (years) & $64(50,71)$ & $66(56,72)$ & 0.0118 \\
\hline BMI $\left(\mathrm{kg} / \mathrm{m}^{2}\right)$ & $23.3(21.4,25.9)$ & $22.05(20.3,25.2)$ & 0.0046 \\
\hline $\begin{array}{l}\text { Etiologies, } \\
\text { HBV/HCV/others }\end{array}$ & $48 / 129 / 78$ & $25 / 150 / 95$ & 0.0153 \\
\hline $\begin{array}{l}\text { Presence of LC, } \\
\text { Yes/no }\end{array}$ & $103 / 152$ & $87 / 183$ & 0.0566 \\
\hline $\begin{array}{l}\text { Total bilirubin } \\
(\mathrm{mg} / \mathrm{dl})\end{array}$ & $0.8(0.6,1.1)$ & $0.75(0.6,1.0)$ & 0.1475 \\
\hline $\begin{array}{l}\text { Serum albumin } \\
(\mathrm{g} / \mathrm{dl})\end{array}$ & $4.3(3.9,4.5)$ & $4.3(4.0,4.5)$ & 0.5278 \\
\hline ALBI score & $-2.9(-3.11,-2.56)$ & $-2.87(-3.11,-2.65)$ & 0.7907 \\
\hline ALBI grade, 1/2/3 & $184 / 64 / 7$ & $215 / 48 / 7$ & 0.1183 \\
\hline $\begin{array}{l}\text { Prothrombin } \\
\text { time }(\%)\end{array}$ & $91.6(80.4,100)$ & $93(84.8,102.1)$ & 0.0684 \\
\hline $\begin{array}{l}\text { Platelet count } \\
\left(\times 10^{4} / \mathrm{mm}^{3}\right)\end{array}$ & $17.6(11.9,22.0)$ & $18.1(13.3,23.3)$ & 0.0488 \\
\hline AST (IU/l) & $25(19,36)$ & $24(19,32)$ & 0.5323 \\
\hline ALT (IU/l) & $24(15,38)$ & $18(13,26)$ & $<0.0001$ \\
\hline $\begin{array}{l}\text { eGFR } \\
\left(\mathrm{ml} / \mathrm{min} / 1.73 \mathrm{~m}^{2}\right)\end{array}$ & $81(69,98)$ & $81.5(67,94)$ & 0.4635 \\
\hline GS $(\mathrm{kg})$ & $34.4(28.5,40.8)$ & $21.05(17.7,24.3)$ & $<0.0001$ \\
\hline SMI $(\mathrm{kg} / \mathrm{m} 2)$ & $7.5(6.95,8.02)$ & $5.91(5.49,6.45)$ & $<0.0001$ \\
\hline $\begin{array}{l}\text { Presence of } \\
\text { sarcopenia, yes/no }\end{array}$ & $23 / 232$ & $38 / 232$ & 0.0774 \\
\hline $\begin{array}{l}\text { Arm circumference } \\
(\mathrm{cm})\end{array}$ & $28(27,30)$ & $27.5(25,30)$ & 0.0055 \\
\hline $\begin{array}{l}\text { Triceps skin } \\
\text { fold thickness }(\mathrm{cm})\end{array}$ & $1.2(0.9,1.5)$ & $1.95(1.4,2.6)$ & $<0.0001$ \\
\hline $\begin{array}{l}\text { Arm muscle } \\
\text { circumference }(\mathrm{cm})\end{array}$ & $24.3(22.8,25.8)$ & $21.3(20.2,22.4)$ & $<0.0001$ \\
\hline $\begin{array}{l}\text { Arm muscle } \\
\text { area }\left(\mathrm{cm}^{2}\right)\end{array}$ & $47.2(41.3,52.8)$ & $36.0(32.5,39.9)$ & $<0.0001$ \\
\hline $\begin{array}{l}\text { Waist } \\
\text { circumference }(\mathrm{cm})\end{array}$ & $89.0(83.0,96.5)$ & $85.0(79.4,94.0)$ & $<0.0001$ \\
\hline $\begin{array}{l}\text { Calf } \\
\text { circumference }(\mathrm{cm})\end{array}$ & $37.1(35.0,39.4)$ & $34.6(32.9,37.5)$ & $<0.0001$ \\
\hline
\end{tabular}

Data are expressed as number or median value (interquartile range). BMI: Body mass index; HBV: hepatitis B virus; HCV: hepatitis C virus; LC: liver cirrhosis; ALBI: albumin-bilirubin; AST: aspartate aminotransferase; ALT: alanine aminotransferase; eGFR: estimated glomerular filtration rate; GS: grip strength; SMI: skeletal muscle index.

review board in our hospital approved this research protocol, and the declaration of Helsinki was strictly adhered to ensure the rights of the patients. An opt out method was used in order to obtain informed consent from the patients.

Anthropometry measurements. In our hospital, anthropometry measurements have been taken by an expert nutrition therapist after full explanation of the need and implications of anthropometry measurements to patients. Anthropometry measurements including $\mathrm{AC}, \mathrm{CC}, \mathrm{TSF}$ and $\mathrm{WC}$ were based on the Japanese anthropometric reference data (JARD) 2001. AMC was calculated using the following formula: AMC $(\mathrm{cm})=\mathrm{AC}-\pi \mathrm{TSF}(\mathrm{cm})$. AMA was calculated using the following formula: AMA $\left(\mathrm{cm}^{2}\right)=(\text { AMC }(\mathrm{cm}))^{2} / 4 \pi$ (Figure 1$)$. 
Table II. Comparison of baseline characteristics between male patients with and without sarcopenia.

\begin{tabular}{|c|c|c|c|}
\hline & $\begin{array}{l}\text { Sarcopenia } \\
\quad(n=23)\end{array}$ & $\begin{array}{l}\text { Non-sarcopenia } \\
\quad(n=232)\end{array}$ & $p$-Value \\
\hline Age (years) & $73(68,77)$ & $62(50,69)$ & 0.0061 \\
\hline BMI $\left(\mathrm{kg} / \mathrm{m}^{2}\right)$ & $20.4(19.7,22.3)$ & $23.8(21.7,26)$ & $<0.0001$ \\
\hline $\begin{array}{l}\text { Presence of LC, } \\
\text { Yes/no }\end{array}$ & $12 / 11$ & $91 / 141$ & 0.2676 \\
\hline $\begin{array}{l}\text { Total bilirubin } \\
(\mathrm{mg} / \mathrm{dl})\end{array}$ & $0.7(0.4,0.8)$ & $0.9(0.63,1.1)$ & 0.0693 \\
\hline $\begin{array}{l}\text { Serum albumin } \\
(\mathrm{g} / \mathrm{dl})\end{array}$ & $4.0(3.5,4.2)$ & $4.3(4.0,4.5)$ & 0.0208 \\
\hline $\begin{array}{l}\text { Prothrombin } \\
\text { time }(\%)\end{array}$ & $92.2(71.9,103.9)$ & $91.5(80.5,99.6)$ & 0.6915 \\
\hline $\begin{array}{l}\text { Platelet count } \\
\left(\times 10^{4} / \mathrm{mm}^{3}\right)\end{array}$ & $16.4(11.6,20.9)$ & $18.1(11.9,22.2)$ & 0.9825 \\
\hline AST (IU/1) & $28(21,46)$ & $24(18.3,34)$ & 0.1373 \\
\hline ALT (IU/l) & $24(14,42)$ & $23.5(15,38)$ & 0.9894 \\
\hline $\begin{array}{l}\text { eGFR } \\
\left(\mathrm{ml} / \mathrm{min} / 1.73 \mathrm{~m}^{2}\right)\end{array}$ & $76(57,86)$ & $82.5(69.3,98)$ & 0.2270 \\
\hline GS (kg) & $23.2(21,24.9)$ & $35.35(30.5,41.4)$ & $<0.0001$ \\
\hline $\operatorname{SMI}\left(\mathrm{kg} / \mathrm{m}^{2}\right)$ & $6.44(5.84,6.84)$ & $7.6(7.1,8.1)$ & $<0.0001$ \\
\hline $\begin{array}{l}\text { Arm circumference } \\
(\mathrm{cm})\end{array}$ & $26.8(26,28.5)$ & $30.3(28.7,32.1)$ & $<0.0001$ \\
\hline $\begin{array}{l}\text { Triceps skin } \\
\text { fold thickness }(\mathrm{cm})\end{array}$ & $1.0(0.9,1.25)$ & $1.2(0.9,1.6)$ & 0.2244 \\
\hline $\begin{array}{l}\text { Arm muscle } \\
\text { circumference }(\mathrm{cm})\end{array}$ & $21(20,22)$ & $23(22,25)$ & $<0.0001$ \\
\hline $\begin{array}{l}\text { Arm muscle } \\
\text { area }\left(\mathrm{cm}^{2}\right)\end{array}$ & $39.3(34.5,43.5)$ & $48(42.8,54.2)$ & $<0.0001$ \\
\hline $\begin{array}{l}\text { Waist } \\
\text { circumference }(\mathrm{cm})\end{array}$ & $83.5(79,91)$ & $89.3(84,97)$ & 0.0393 \\
\hline $\begin{array}{l}\text { Calf } \\
\text { circumference }(\mathrm{cm})\end{array}$ & $34(32.9,34.9)$ & $37.6(35.5,39.6)$ & $<0.0001$ \\
\hline
\end{tabular}

Data are expressed as number or median value (interquartile range). BMI: Body mass index; LC: liver cirrhosis; AST: aspartate aminotransferase; ALT: alanine aminotransferase, eGFR: estimated glomerular filtration rate; GS; grip strength; SMI: skeletal muscle index.

Statistical analysis. The JMP 14 software (SAS Institute Inc., Cary, NC, USA) was used to statistically analyze the data. For the numerical variables, Mann-Whitney $U$-test or Student's $t$-test, or Pearson's correlation coefficient $r$ was used to assess group characteristics when appropriate. For the categorical variables, Fisher's exact test or Pearson $\chi^{2}$ test was used to assess group characteristics when appropriate. Receiver operating characteristic curve (ROC) analysis and area under the ROC (AUC) results were presented along with the corresponding optimal cutoff point, sensitivity and specificity. Data were demonstrated as median value [interquartile range (IQR)]. The statistical significancelevel was set at $p<0.05$.

\section{Results}

Baseline features. Baseline features of the study cohort $[\mathrm{n}=255$ males; median (IQR) age $=64(50,71)$ years $]$ and $\mathrm{n}=270$ females [median (IQR) age $=66(56,72)$ years; $p=0.0118$ ] are presented in Table I. LC was identified at
Table III. Comparison of baseline characteristics between female patients with and without sarcopenia.

\begin{tabular}{|c|c|c|c|}
\hline & $\begin{array}{l}\text { Sarcopenia } \\
\quad(\mathrm{n}=38)\end{array}$ & $\begin{array}{l}\text { Non-sarcopenia } \\
\quad(\mathrm{n}=232)\end{array}$ & $p$-Value \\
\hline Age (years) & $74(68,78)$ & $63(54,71)$ & $<0.0001$ \\
\hline BMI $\left(\mathrm{kg} / \mathrm{m}^{2}\right)$ & $20.6(19.3,21.6)$ & $22.5(20.4,25.8)$ & $<0.0001$ \\
\hline $\begin{array}{l}\text { Presence of LC, } \\
\text { Yes/no }\end{array}$ & $13 / 25$ & $74 / 158$ & 0.8518 \\
\hline $\begin{array}{l}\text { Total bilirubin } \\
(\mathrm{mg} / \mathrm{dl})\end{array}$ & $0.65(0.58,0.9)$ & $0.8(0.6,1.0)$ & 0.4042 \\
\hline $\begin{array}{l}\text { Serum albumin } \\
(\mathrm{g} / \mathrm{dl})\end{array}$ & $4.1(3.9,4.4)$ & $4.3(4.0,4.5)$ & 0.0292 \\
\hline $\begin{array}{l}\text { Prothrombin } \\
\text { time }(\%)\end{array}$ & $88.6(83.2,100.2)$ & $93.8(85.4,102.2)$ & 0.6417 \\
\hline $\begin{array}{l}\text { Platelet count } \\
\left(\times 10^{4} / \mathrm{mm}^{3}\right)\end{array}$ & $17.4(14.3,21.8)$ & $18.2(13.2,23.3)$ & 0.7721 \\
\hline AST (IU/l) & $25(21,35.3)$ & $24(19,31)$ & 0.8194 \\
\hline ALT (IU/l) & $17.5(13,29)$ & $18(13,24.8)$ & 0.4646 \\
\hline $\begin{array}{l}\text { eGFR } \\
\left(\mathrm{ml} / \mathrm{min} / 1.73 \mathrm{~m}^{2}\right)\end{array}$ & $72(64.8,92.3)$ & $82.5(68,94)$ & 0.0763 \\
\hline GS $(\mathrm{kg})$ & $15.9(12.9,16.8)$ & $21.8(19.1,24.6)$ & $<0.0001$ \\
\hline $\operatorname{SMI}\left(\mathrm{kg} / \mathrm{m}^{2}\right)$ & $5.26(4.88,5.46)$ & $6.07(5.7,6.5)$ & $<0.0001$ \\
\hline $\begin{array}{l}\text { Arm circumference } \\
(\mathrm{cm})\end{array}$ & $26(23,27)$ & $28(26,31)$ & $<0.0001$ \\
\hline $\begin{array}{l}\text { Triceps skin } \\
\text { fold thickness }(\mathrm{cm})\end{array}$ & $1.5(1.1,2.1)$ & $2.0(1.5,2.7)$ & 0.0005 \\
\hline $\begin{array}{l}\text { Arm muscle } \\
\text { circumference }(\mathrm{cm})\end{array}$ & $20(19.2,21.2)$ & $21.5(20.4,22.7)$ & 0.0002 \\
\hline $\begin{array}{l}\text { Arm muscle } \\
\text { area }\left(\mathrm{cm}^{2}\right)\end{array}$ & $31.9(29.4,35.8)$ & $36.9(33.2,40.9)$ & 0.0056 \\
\hline $\begin{array}{l}\text { Waist } \\
\text { circumference }(\mathrm{cm})\end{array}$ & $82.3(77.2,86.2)$ & $86(80,95)$ & 0.0055 \\
\hline $\begin{array}{l}\text { Calf } \\
\text { circumference }(\mathrm{cm})\end{array}$ & $31.6(29.9,33.4)$ & $35.1(33.5,37.9)$ & $<0.0001$ \\
\hline
\end{tabular}

Data are expressed as number or median value (interquartile range). BMI: Body mass index; LC: liver cirrhosis; AST: aspartate aminotransferase; ALT: alanine aminotransferase; eGFR: estimated glomerular filtration rate; GS: grip strength; SMI: skeletal muscle index.

baseline in 103 male cases (40.4\%) and 87 female cases (32.2\%). Hepatitis C virus was identified in $50.6 \%$ males $(129 / 255)$ and $55.6 \%(150 / 270)$ females. Albumin-bilirubin (ALBI) grade 1 was found in the majority of males $(184 / 255$, $72.2 \%)$ and females $(215 / 270,79.6 \%)$.

In males, the median (IQR) GS was $34.4(28.5,40.8) \mathrm{kg}$, while in females, it was $21.05(17.7,24.3) \mathrm{kg}$. Forty men $(15.7 \%)$ and 70 women $(25.9 \%)$ had a GS decrease (GS: $<26$ $\mathrm{kg}$ for men and $<18 \mathrm{~kg}$ for women). In males, the median (IQR) SMI was $7.5(6.95,8.02) \mathrm{kg} / \mathrm{m}^{2}$, while in females, it was $5.91(5.49,6.45) \mathrm{kg} / \mathrm{m}^{2}$. Sixty-four men $(25.1 \%)$ and 98 women $(36.3 \%)$ had SMI decrease (SMI: $<7.0 \mathrm{~kg} / \mathrm{m}^{2}$ for men and $<5.7 \mathrm{~kg} / \mathrm{m}^{2}$ for women). Sarcopenia was identified in 23 male patients $(9.0 \%)$ and 38 female patients (14.1\%).

In terms of anthropometric parameters, the median (IQR) AC $(\mathrm{cm}), \operatorname{TSF}(\mathrm{cm}), \operatorname{AMC}(\mathrm{cm}), \operatorname{AMA}\left(\mathrm{cm}^{2}\right), \mathrm{WC}(\mathrm{cm}), \mathrm{CC}$ 


\section{A Male $(\mathbf{n}=\mathbf{2 5 5})$}
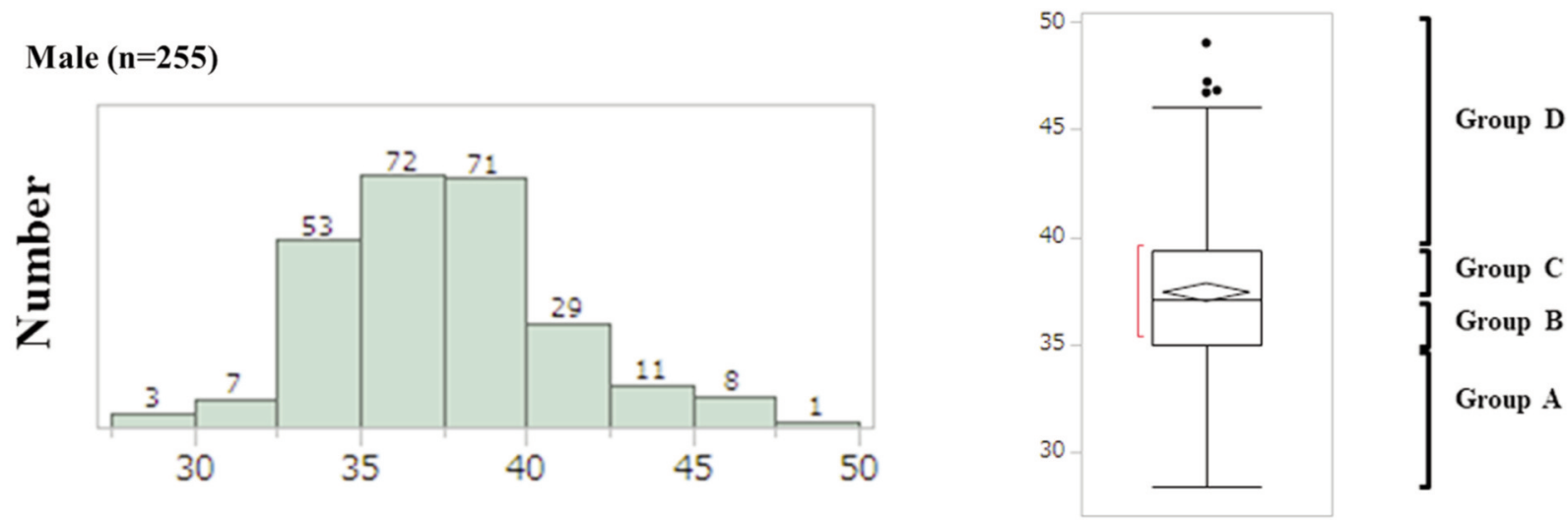

Calf circumference $(\mathrm{cm})$

\section{B Female $(\mathrm{n}=\mathbf{2 7 0})$}
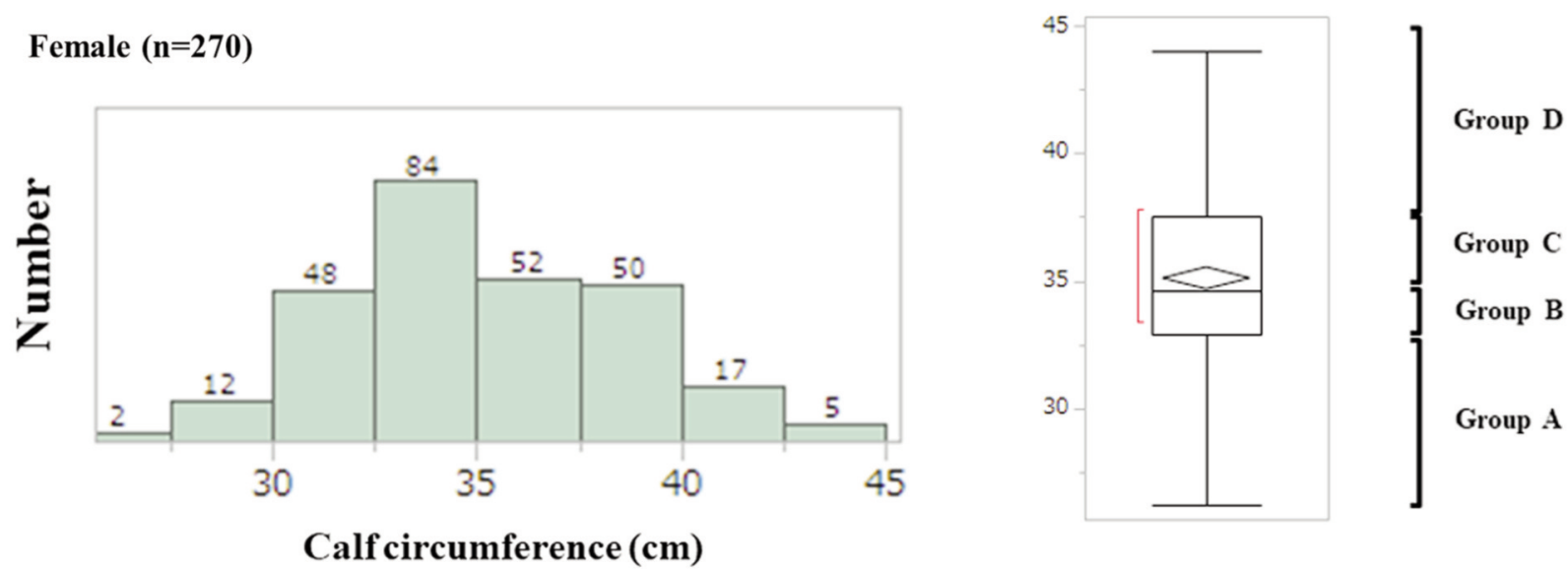

Figure 2. Distribution of $C C$ in males $(A)$ and females $(B)$. In males, there were 66 patients in group A [CC: $\leq 35.0 \mathrm{~cm}$ (first quantile)], 64 in group $B$ [CC: $>35.0 \mathrm{~cm}, \leq 37.1 \mathrm{~cm}$ (median)], 62 in group $C[C C:>37.1 \mathrm{~cm}, \leq 39.4$ (third quantile)] and 63 in group D $(C C:>39.4 \mathrm{~cm})$. In females, there were 68 patients in group A [CC: $\leq 32.9 \mathrm{~cm}$ (first quantile)], 70 in group B [CC: $>32.9 \mathrm{~cm}, \leq 34.6 \mathrm{~cm}$ (median)], 67 in group C [CC: $>34.6 \mathrm{~cm}$, $\leq 37.5$ (third quantile)] and 65 in group $D(C C:>37.5 \mathrm{~cm})$.

$(\mathrm{cm})$ and BMI $\left(\mathrm{kg} / \mathrm{m}^{2}\right)$ in males vs. females were $28(27,30)$ cm vs. $27.5(25,30) \mathrm{cm}(p=0.0055), 1.2(0.9,1.5) \mathrm{cm} v s$. $1.95(1.4,2.6) \mathrm{cm}(p<0.0001), 24.3(22.8,25.8) \mathrm{cm} v s .21 .3$ $(20.2,22.4) \mathrm{cm}(p<0.0001), 47.2(41.3,52.8) \mathrm{cm}^{2} v s .36 .0$ $(32.5,39.9) \mathrm{cm}^{2}(p<0.0001), 89.0(83.0,96.5) \mathrm{cm} \mathrm{vs.} 85.0$ $(79.4,94.0) \mathrm{cm}(p<0.0001), 37.1(35.0,39.4) \mathrm{cm} \mathrm{vs.} 34.6$ $(32.9,37.5) \mathrm{cm}(p<0.0001)$ and $23.3(21.4,25.9) \mathrm{kg} / \mathrm{m}^{2} v s$. $22.05(20.3,25.2) \mathrm{kg} / \mathrm{m}^{2}(p=0.0046)$, respectively.

In males, the differences of baseline characteristics between sarcopenic patients and non-sarcopenic patients reached significance in terms of age $(p=0.0061)$, BMI $(p<0.0001)$, serum albumin $(p=0.0208), \mathrm{GS}(p<0.0001)$, SMI $(p<0.0001)$, AC $(p<0.0001)$, AMC $(p<0.0001)$, AMA $(p<0.0001)$, WC $(p=0.0393)$ and CC $(p<0.0001)$ (Table II). In females, the differences of baseline characteristics between sarcopenic patients and non-sarcopenic patients reached significance in terms of age $(p<0.0001)$, BMI $(p<0.0001)$, serum albumin $(p=0.0292), \mathrm{GS}(p<0.0001), \mathrm{SMI}(p<0.0001)$, AC $(p<0.0001)$, TSF $(p=0.0005)$, AMC $(p=0.0002)$, AMA $(p=0.0056)$, WC $(p=0.0055)$ and CC $(p<0.0001)$ (Table III).

Distributions of $C C(\mathrm{~cm})$ in males and females. Distributions of $\mathrm{CC}$ in males and females are shown in Figure 2A and B. In males, there were 66 patients in group A [CC: $\leq 35.0 \mathrm{~cm}$ (first quantile)], 64 in group B [CC: $>35.0 \mathrm{~cm}, \leq 37.1 \mathrm{~cm}$ (median)], 62 in group C $[\mathrm{CC}:>37.1 \mathrm{~cm}, \leq 39.4$ (third quantile)] and 63 in group D $(\mathrm{CC}:>39.4 \mathrm{~cm})$. In females, there were 68 patients in group A [CC: $\leq 32.9 \mathrm{~cm}$ (first quantile)], 70 in group $\mathrm{B}[\mathrm{CC}:>32.9 \mathrm{~cm}, \leq 34.6 \mathrm{~cm}$ (median)], 67 in group $\mathrm{C}[\mathrm{CC}:>34.6 \mathrm{~cm}, \leq 37.5$ (third quantile)] and 65 in group D $(\mathrm{CC}:>37.5 \mathrm{~cm})$. In males, the proportion of sarcopenia was well stratified among groups of A $(19 / 66,28.79 \%), \mathrm{B}(4 / 64,6.25 \%), \mathrm{C}(0 / 62)$ and D $(0 / 63)$ (overall $p<0.0001)$ (Figure $3 \mathrm{~A})$. In females, the 

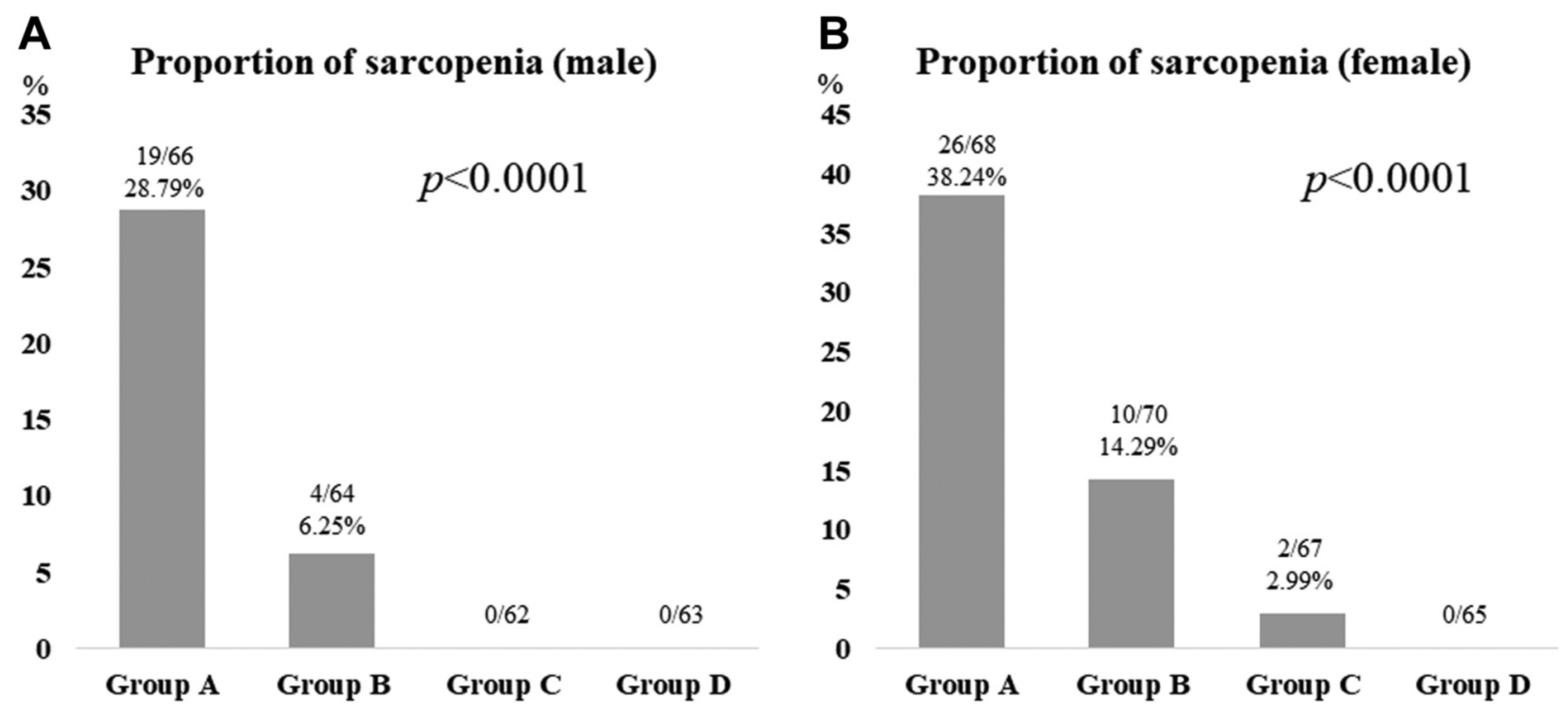

Figure 3. The proportion of sarcopenia among groups of $A, B, C$ and $D$ in males $(A)$ and females $(B)$.
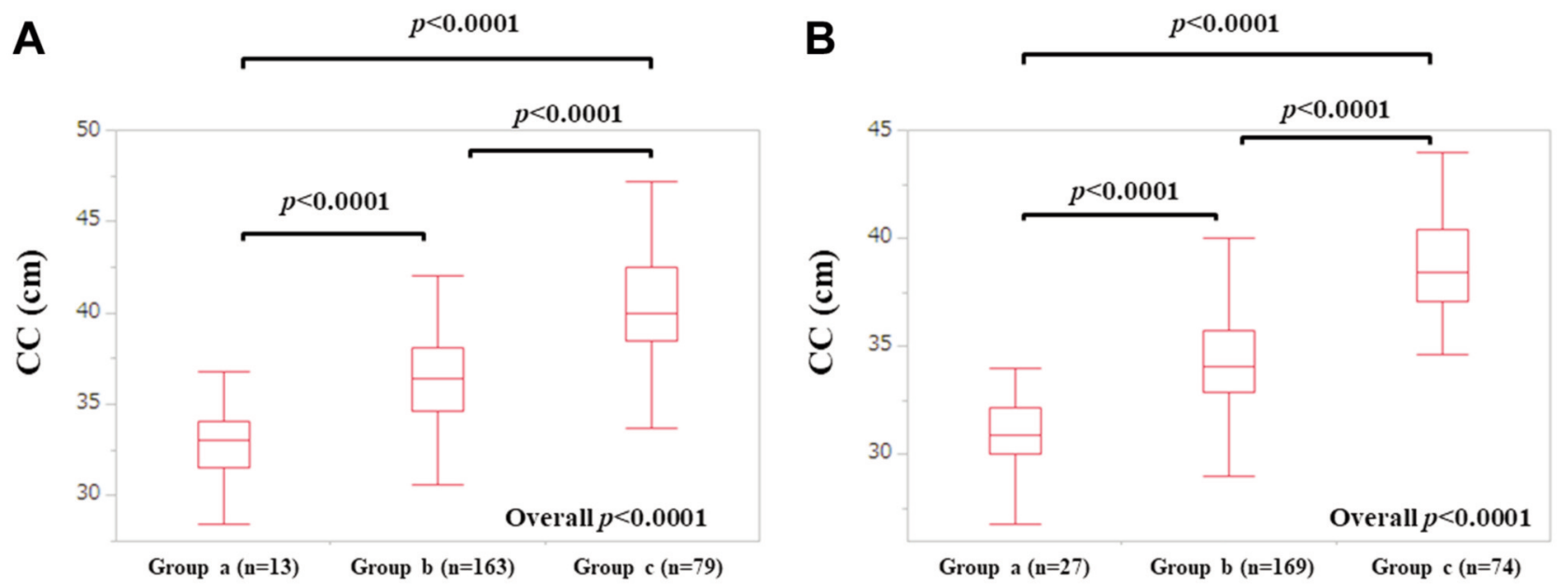

Figure 4. CC according to BMI in males (A) and females (B). Our study cohort was classified into 3 groups according to BMI; patients with BMI $<18.5 \mathrm{~kg} / \mathrm{m}^{2}$ (group a); those with BMI 18.5 to $25.0 \mathrm{~kg} / \mathrm{m}^{2}$ (group b); those with BMI $\geq 25.0 \mathrm{~kg} / \mathrm{m}^{2}$ (group c).

proportion of sarcopenia was also well stratified among groups of A $(26 / 68,38.24 \%), \mathrm{B}(10 / 70,14.29 \%), \mathrm{C}(2 / 67$, $2.99 \%)$ and $\mathrm{D}(0 / 65)$ (overall $p<0.0001)$ (Figure 3B).

CC according to BMI in males and females. Our study cohort was classified into 3 groups according to BMI; patients with BMI $<18.5 \mathrm{~kg} / \mathrm{m}^{2}$ (group a); those with BMI 18.5 to 25.0 $\mathrm{kg} / \mathrm{m}^{2}$ (group b); those with BMI $\geq 25.0 \mathrm{~kg} / \mathrm{m}^{2}$ (group c) (39). In males, the median (IQR) CC in group a $(n=13), b(n=163)$ and $\mathrm{c}(\mathrm{n}=79)$ were: $33.0(31.5,34.1) \mathrm{cm}, 36.4(34.6,38.1) \mathrm{cm}$ and $40.0(38.5,42.5) \mathrm{cm}$ ( $p$ values: a vs. b. $p<0.0001$; b vs. c, $p<0.0001$; c vs. a, $p<0.0001$; overall $p<0.0001)$, respectively. In females, the median (IQR) $\mathrm{CC}$ in group a $(\mathrm{n}=27), \mathrm{b}(\mathrm{n}=169)$ and $\mathrm{c}(\mathrm{n}=74)$ were: $30.9(30.0,32.2) \mathrm{cm}$, $34.1(32.85,35.75) \mathrm{cm}$ and $38.45(37.1,40.425) \mathrm{cm}(p$ values: a vs. b. $p<0.0001$; b vs. c, $p<0.0001$; c vs. a, $p<0.0001$; overall $p<0.0001$ ), respectively (Figure 4A and B).

Correlation between 7 anthropometric parameters and SMI in males. The correlation coefficients between 7 anthropometric parameters and SMI in males were: $r=0.72$ in $\mathrm{AC}(p<0.0001)$, $r=0.36$ in TSF $(p<0.0001), r=0.68$ in AMC $(p<0.0001), r=0.79$ 
Table IV. Correlation between anthropometry parameters and SMI and GS in males.

\begin{tabular}{lcclrr}
\hline \multirow{2}{*}{ Male } & \multicolumn{2}{c}{ SMI } & & \multicolumn{2}{c}{ GS } \\
\cline { 2 - 3 } \cline { 5 - 6 } & r & $p$-Value & & \multicolumn{1}{c}{$\mathrm{r}$} & $p$-Value \\
\hline AC & 0.72 & $<0.0001$ & & 0.44 & $<0.0001$ \\
TSF & 0.36 & $<0.0001$ & & 0.063 & 0.3168 \\
AMC & 0.68 & $<0.0001$ & & 0.55 & $<0.0001$ \\
CC & 0.79 & $<0.0001$ & & 0.42 & $<0.0001$ \\
WC & 0.60 & $<0.0001$ & & 0.028 & 0.6587 \\
AMA & 0.68 & $<0.0001$ & & 0.54 & $<0.0001$ \\
BMI & 0.77 & $<0.0001$ & & 0.21 & 0.0006 \\
\hline
\end{tabular}

in $\mathrm{CC}(p<0.0001), r=0.60$ in WC $(p<0.0001), r=0.68$ in AMA $(p<0.0001)$ and $r=0.77$ in BMI $(p<0.0001)$ (Table IV).

Correlation between 7 anthropometric parameters and GS in males. The correlation coefficients between 7 anthropometric parameters and GS in males were: $r=0.44$ in AC $(p<0.0001)$, $r=0.063$ in TSF $(p=0.3168), r=0.55$ in AMC $(p<0.0001)$, $r=0.42$ in $\mathrm{CC}(p<0.0001), r=0.028$ in WC $(p=0.6587), r=0.54$ in AMA $(p<0.0001)$ and $r=0.21$ in BMI $(p=0.0006)$ (Table IV).

Correlation between 7 anthropometric parameters and SMI in females. The correlation coefficients between 7 anthropometric parameters and SMI in females were: $r=0.62$ in AC $(p<0.0001)$, $r=0.48$ in TSF $(p<0.0001), r=0.52$ in AMC $(p<0.0001), r=0.83$ in CC $(p<0.0001), r=0.61$ in WC $(p<0.0001), r=0.39$ in AMA $(p<0.0001)$ and $r=0.75$ in BMI $(p<0.0001)$ (Table V).

Correlation between 7 anthropometric parameters and GS in females. The correlation coefficients between 7 anthropometric parameters and GS in females were: $r=0.15$ in AC $(p=0.0154)$, $r=0.11$ in TSF $(p=0.0779), r=0.14$ in $\operatorname{AMC}(p=0.0214), r=0.34$ in CC $(p<0.0001), r=0.058$ in WC $(p=0.3407), r=0.085$ in $\operatorname{AMA}(p=0.1620)$ and $r=0.12$ in BMI $(p=0.0488)$ (Table V).

ROC analysis of 7 anthropometric parameters for the presence of sarcopenia in males. Results of ROC analysis of 7 anthropometric parameters for the presence of sarcopenia in males are shown in Table VI (corresponding AUC, optimal cutoff point, sensitivity and specificity). CC had the highest AUC (0.88) for sarcopenia, followed by AMC $(\mathrm{AUC}=0.84)$ and AMA $(\mathrm{AUC}=0.84)$.

ROC analysis of 7 anthropometric parameters for the presence of sarcopenia in females. Results of ROC analysis of 7 anthropometric parameters for the presence of sarcopenia in females were shown in Table VII (corresponding AUC, optimal cutoff point, sensitivity and specificity). CC had the
Table V. Correlation between anthropometry parameters and SMI and $G S$ in females.

\begin{tabular}{lccccr}
\hline Female & \multicolumn{2}{c}{ SMI } & & \multicolumn{2}{c}{ GS } \\
\cline { 2 - 3 } \cline { 5 - 6 } & $\mathrm{r}$ & $p$-Value & & $\mathrm{r}$ & $p$-Value \\
\hline AC & 0.62 & $<0.0001$ & & 0.15 & 0.0154 \\
TSF & 0.48 & $<0.0001$ & & 0.11 & 0.0779 \\
AMC & 0.52 & $<0.0001$ & & 0.14 & 0.0214 \\
CC & 0.83 & $<0.0001$ & & 0.34 & $<0.0001$ \\
WC & 0.61 & $<0.0001$ & & 0.058 & 0.3407 \\
AMA & 0.39 & $<0.0001$ & & 0.085 & 0.1620 \\
BMI & 0.75 & $<0.0001$ & & 0.12 & 0.0488 \\
\hline
\end{tabular}

SMI: Skeletal muscle index; GS: grip strength; AC: arm circumference; TSF: triceps skin fold thickness; AMC: arm muscle circumference, CC: calf circumference; WC: waist circumference; AMA: arm muscle area; BMI: body mass index.

highest AUC (0.86) for sarcopenia, followed by AMC $(\mathrm{AUC}=0.75)$ and AMA (AUC=0.75).

\section{Discussion}

As mentioned above, anthropometry easily and non-invasively provides an assessment of size and composition of the human body (25). Especially in facilities without BIA or computed tomography, anthropometry is of great significance. The revised AWGS guidelines propose separate algorithms for community $v s$. hospital settings (29). In community settings, assessment of muscle mass is not required for the diagnosis of sarcopenia in the revised AWGS guidelines. In both community and hospital settings, first screening for possible sarcopenia using CC or questionnaire is recommended, but in the Japanese Society of hepatology criteria for sarcopenia in liver disease, such recommendation is not found $(19,29)$. To elucidate the relationship between CC and sarcopenia in CLD patients is important. To the best of our knowledge, this is the largest study elucidating the relationship between $\mathrm{CC}$ and sarcopenia in patients with CLDs.

In our study, the proportion of sarcopenia was well stratified by $\mathrm{CC}$ regardless of gender and $\mathrm{CC}$ had the highest AUC for sarcopenia (0.88 in males and 0.86 in females) among the 7 anthropometry parameters. Hiraoka, et al. reported that the AUC values for muscle mass decrease of finger-circle test were 0.654 in males and 0.698 in females (33). Considering these, our results denoted that $\mathrm{CC}$ can be a useful anthropometry measurement for sarcopenia in CLDs. In addition, measurement of CC is easily available in the clinical settings and it should thus be highly recommended although the current JSH criteria for sarcopenia in CLDs do not. The cutoff values of CC for sarcopenia in the revised AWGS guidelines are $34 \mathrm{~cm}$ in 
Nishikawa et al: Calf Circumference and Sarcopenia

Table VI. ROC analysis of anthropometrical parameters for the presence of sarcopenia in males.

\begin{tabular}{lcccc}
\hline Male & AUC & Cutoff & Sensitivity & Specificity \\
\hline AC & 0.82 & $27 \mathrm{~cm}$ & 0.913 & 0.668 \\
TSF & 0.60 & $12.5 \mathrm{~mm}$ & 0.783 & 0.427 \\
AMC & 0.84 & $23.6 \mathrm{~cm}$ & 0.913 & 0.668 \\
CC & 0.88 & $35.4 \mathrm{~cm}$ & 0.913 & 0.776 \\
WC & 0.65 & $84.2 \mathrm{~cm}$ & 0.565 & 0.741 \\
AMA & 0.84 & $44.2 \mathrm{~cm}^{2}$ & 0.913 & 0.677 \\
BMI & 0.79 & $21.7 \mathrm{~kg} / \mathrm{m}^{2}$ & 0.739 & 0.750 \\
\hline
\end{tabular}

males and $33 \mathrm{~cm}$ in females. However, our ROC analysis indicated that the optimal cutoff values of CC were $35.4 \mathrm{~cm}$ in males and $33.8 \mathrm{~cm}$ in females, which are higher than AWGS data (29). This is probably due to the difference in the target population between the AWGS cohort (elderly patients only) and our cohort [median (IQR) age that was $64(50,71)$ years]. Age restriction for assessing sarcopenia is not included in the current JSH criteria (19).

The close correlation between CC and BMI also gave us some insights for sarcopenia in CLDs. CC is used to mainly evaluate muscle mass (correlation coefficient of our data between CC and SMI was: $r=0.79$ in males and $r=0.83$ in females) and BMI is used to mainly evaluate fat mass. BMI can be critical for assessing sarcopenia in CLDs, while caution should be exercised for the presence of sarcopenic obese patients (40). In this study, of the 175 male patients with visceral obesity (WC $\geq 85 \mathrm{~cm}), 10(5.71 \%)$ had sarcopenia, while of the 91 female patients with visceral obesity (WC $\geq 90$ $\mathrm{cm}), 5$ (5.49\%) had sarcopenia. However, CC significantly correlated with GS both in males and females although the correlation coefficients $(r=0.42$ in males and $r=0.34$ in females) were not so impressive compared with SMI. Muscle mass appears to reflect muscle strength to some extent.

A recent meta-analysis has reported that although the screening specificity performance of SARC-F for sarcopenia was high, its sensitivity was low (pooled results of sensitivity and specificity, 0.21 and 0.90 ) (41). While in our study, sensitivity and specificity of CC were 0.913 and 0.776 , respectively. Hiraoka et al. reported that SARC-F score in combination with muscle strength decline and CC can be an easy and simple method for assessing muscle volume loss in CLD patients, which may be linked to our results (32). The revised AWGS guidelines recommend SARC-Calf as a screening tool for sarcopenia (29). Taking the meta-analysis of SARC-F and our current data (i.e., high sensitivity of CC for sarcopenia) into consideration, SARC-Calf should be recommended as a screening tool for sarcopenia in CLDs.

According to the Japanese anthropometric reference data (JARD) 2001, the median BMI, AC, TSF, AMC, CC, and
Table VII. ROC analysis of anthropometrical parameters for the presence of sarcopenia in females.

\begin{tabular}{lcccc}
\hline Male & AUC & Cutoff & Sensitivity & Specificity \\
\hline AC & 0.74 & $27 \mathrm{~cm}$ & 0.816 & 0.552 \\
TSF & 0.67 & $15 \mathrm{~mm}$ & 0.526 & 0.737 \\
AMC & 0.75 & $20.4 \mathrm{~cm}$ & 0.632 & 0.750 \\
CC & 0.86 & $33.8 \mathrm{~cm}$ & 0.895 & 0.720 \\
WC & 0.64 & $86.9 \mathrm{~cm}$ & 0.790 & 0.478 \\
AMA & 0.75 & $36.2 \mathrm{~cm}^{2}$ & 0.842 & 0.535 \\
BMI & 0.71 & $21.9 \mathrm{~kg} / \mathrm{m}^{2}$ & 0.842 & 0.560 \\
\hline
\end{tabular}

AMC in Japanese adult males are $22.5 \mathrm{~kg} / \mathrm{m}^{2}, 27.2 \mathrm{~cm}, 10.0$ $\mathrm{mm}, 23.7 \mathrm{~cm}, 35.0 \mathrm{~cm}, 44.8 \mathrm{~cm}^{2}$, respectively, while those in Japanese adult females are $20.7 \mathrm{~kg} / \mathrm{m}^{2}, 25.2 \mathrm{~cm}, 15.0 \mathrm{~mm}$, $20.2 \mathrm{~cm}, 32.7 \mathrm{~cm}, 32.4 \mathrm{~cm}^{2}$, respectively. The median BMI, $\mathrm{AC}, \mathrm{TSF}, \mathrm{AMC}, \mathrm{CC}, \mathrm{AMC}$ in our male patients were 23.3 $\mathrm{kg} / \mathrm{m}^{2}, 28.0 \mathrm{~cm}, 12.0 \mathrm{~mm}, 24.3 \mathrm{~cm}, 37.1 \mathrm{~cm}, 47.2 \mathrm{~cm}^{2}$, indicating that all values of these parameters were higher compared with JARD 2001 male data. The median BMI, AC, TSF, AMC, CC, AMC in our female patients were $22.1 \mathrm{~kg} / \mathrm{m}^{2}$, $27.5 \mathrm{~cm}, 19.5 \mathrm{~mm}, 21.3 \mathrm{~cm}, 34.6 \mathrm{~cm}, 36.0 \mathrm{~cm}^{2}$, indicating that all values of these parameters were also higher compared with JARD 2001 female data. The physique of Japanese CLD patients seems to be getting better than before. These data may reflect improvements in therapies for underlying liver diseases or the changes in disease structure $(42,43)$.

Several limitations associated with the study should be mentioned. Firstly, this was a retrospective cross-sectional observational study which only enrolled patients from a single hospital. Secondly, our data included population data on CLDs in Japan, and further studies on other ethnic backgrounds are necessary to confirm and expand its adaptation to these other backgrounds. Thirdly, patients with large ascites who may have sarcopenia were excluded due to the limits of BIA, allowing a possibility for bias. Finally, owing to the cross-sectional nature of our study, the causal relationship between CC decrease and sarcopenia is unclear. Our data should be interpreted with caution. The study results nevertheless denoted that sarcopenia and CC in CLDs have a close relationship. In conclusion, $\mathrm{CC}$ can be a helpful screening tool for predicting sarcopenia in CLDs.

\section{Conflicts of Interest}

The Authors have no conflicts of interest to declare regarding this study.

\section{Authors' Contributions}

Data curation, Hiroki Nishikawa, Kazunori Yoh, Hirayuki Enomoto, Yoshinori Iwata, Yoshiyuki Sakai, Kyohei Kishino, Yoshihiro 
Shimono, Naoto Ikeda, Tomoyuki Takashima, Nobuhiro Aizawa, Ryo Takata, Kunihiro Hasegawa, Takashi Koriyama, Yukihisa Yuri and Takashi Nishimura; Formal analysis, Hiroki Nishikawa; Supervision, Hirayuki Enomoto, Shuhei Nishiguchi and Hiroko Iijima; Writing - original draft, Hiroki Nishikawa and Kazunori Yoh; Writing - review \& editing, Hiroki Nishikawa.

\section{Acknowledgements}

The Authors would like to thank Yasuko Higuchi in our hospital for the anthropometry measurement. This work was partly granted by Hyogo Innovative Challenge, Hyogo college of medicine, Japan.

\section{References}

1 Dasarathy S and Merli M: Sarcopenia from mechanism to diagnosis and treatment in liver disease. J Hepatol 65: 12321244, 2016. PMID: 27515775. DOI: 10.1016/j.jhep.2016.07.040

2 Nishikawa H, Enomoto H, Yoh K, Iwata Y, Sakai Y, Kishino K, Ikeda N, Takashima T, Aizawa N, Takata R, Hasegawa K, Ishii $\mathrm{N}$, Yuri Y, Nishimura T, Iijima $\mathrm{H}$ and Nishiguchi S: Combined albumin-bilirubin grade and skeletal muscle mass as a predictor in liver cirrhosis. J Clin Med 8(6): pii: E782, 2019. PMID: 31159435. DOI: $10.3390 / \mathrm{jcm} 8060782$

3 Nishikawa H, Enomoto H, Yoh K, Iwata Y, Sakai Y, Kishino K, Ikeda N, Takashima T, Aizawa N, Takata R, Hasegawa K, Ishii $\mathrm{N}$, Yuri Y, Nishimura T, Iijima $\mathrm{H}$ and Nishiguchi S: Healthrelated quality of life in chronic liver diseases: a strong impact of hand grip strength. J Clin Med 7(12): pii: E553, 2018. PMID: 30558298. DOI: $10.3390 / \mathrm{jcm} 7120553$

4 Aby ES and Saab S: Frailty, sarcopenia, and malnutrition in cirrhotic patients. Clin Liver Dis 23(4): 589-605, 2019. PMID: 31563213. DOI: 10.1016/j.cld.2019.06.001

5 Williams FR, Berzigotti A, Lord JM, Lai JC and Armstrong MJ: Review article: impact of exercise on physical frailty in patients with chronic liver disease. Aliment Pharmacol Ther, 2019. PMID: 31502264. DOI: 10.1111/apt.15491

6 Ebadi M, Bhanji RA, Mazurak VC and Montano-Loza AJ: Sarcopenia in cirrhosis: from pathogenesis to interventions. J Gastroenterol 54(10): 845-859, 2019. PMID: 31392488. DOI: 10.1007/s00535-019-01605-6

7 Poh HO, Amber Hager, Vera CM, Khaled Dajani, Ravi Bhargava, Susan MG and Diana RM: Sarcopenia in chronic liver disease: impact on outcomes. Liver Transpl 25(9): 1422-1438, 2019. PMID: 31242345 . DOI: 10.1002/lt.25591

8 Hsu CS and Kao JH: Sarcopenia and chronic liver diseases. Expert Rev Gastroenterol Hepatol 12(12): 1229-1244, 2018. PMID: 30791794. DOI: 10.1080/17474124.2018.1534586

9 Hanai T, Shiraki M, Imai K, Suetsugu A, Takai K, Moriwaki H and Masahito $\mathrm{S}$ : Reduced handgrip strength is predictive of poor survival among patients with liver cirrhosis: A sex-stratified analysis. Hepatol Res 49(12): 1414-1426, 2019. PMID: 31408558. DOI: 10.1111/hepr.13420

10 Nishikawa H, Enomoto H, Ishii A, Iwata Y, Miyamoto Y, Ishii N, Yuri, Takata R, Hasegawa K, Nakano C, Nishimura T, Yoh K, Aizawa N, Sakai Y, Ikeda N, Takashima T, Iijima H and Nishiguchi S: Prognostic significance of low skeletal muscle mass compared with protein-energy malnutrition in liver cirrhosis. Hepatol Res 47(10): 1042-1052, 2017. PMID: 27862791. DOI: $10.1111 /$ hepr.12843
11 Bunchorntavakul $\mathrm{C}$ and Reddy KR: Review article: malnutrition/sarcopenia and frailty in patients with cirrhosis. Aliment Pharmacol Ther 51(1): 64-77, 2020. PMID: 31701570. DOI: 10.1111/apt.15571

12 Nardelli S, Gioia S, Faccioli J, Riggio O and Ridola L: Sarcopenia and cognitive impairment in liver cirrhosis: A viewpoint on the clinical impact of minimal hepatic encephalopathy. World J Gastroenterol 25(35): 5257-5265, 2019. PMID: 31558871. DOI: 10.3748/wjg.v25.i35.5257

13 Wijarnpreecha K, Werlang M, Panjawatanan P, Kroner PT, Cheungpasitporn W, Lukens FJ, Pungpapong S and Ungprasert P: Association between sarcopenia and hepatic encephalopathy: A systematic review and meta-analysis. Ann Hepatol pii: S16652681(19)32193-3, 2019. PMID: 31422030. DOI: 10.1016/ j.aohep.2019.06.007

14 Kitajima Y, Takahashi H, Akiyama T, Murayama K, Iwane S, Kuwashiro, Tanaka K, Kawazoe S, Ono N, Eguchi T, Anzai K and Eguchi Y: Supplementation with branched-chain amino acids ameliorates hypoalbuminemia, prevents sarcopenia, and reduces fat accumulation in the skeletal muscles of patients with liver cirrhosis. J Gastroenterol 53(3): 427-437, 2018. PMID: 28741271. DOI: $10.1007 / \mathrm{s} 00535-017-1370-\mathrm{x}$

15 Namba M, Hiramatsu A, Aikata H, Kodama K, Uchikawa S, Ohya K, Morio K, Fujino H, Nakahara T, Murakami E, Yamauchi M, Kawaoka T, Tsuge M, Imamura M and Chayama $\mathrm{K}$ : Management of refractory ascites attenuates muscle mass reduction and improves survival in patients with decompensated cirrhosis. J Gastroenterol 55(2): 217-226, 2020. PMID: 31485782. DOI: $10.1007 / \mathrm{s} 00535-019-01623-4$

16 Hiraoka A, Aibiki T, Okudaira T, Toshimori A, Kawamura T, Nakahara H, Suga Y, Azemoto N, Miyata H, Miyamoto Y, Ninomiya T, Hirooka M, Abe M, Matsuura B, Hiasa Y and Michitaka K: Muscle atrophy as pre-sarcopenia in Japanese patients with chronic liver disease: computed tomography is useful for evaluation. J Gastroenterol 50(12): 1206-1213, 2015. PMID: 25820219. DOI: 10.1007/s00535-015-1068-x

17 Maurice J and Pinzani M: The stratification of cirrhosis. Hepatol Res, 2020. PMID: 32072721. DOI: 10.1111/hepr.13493

18 Nagamatsu A, Kawaguchi T, Hirota K, Koya S, Tomita M, Hashida R, Kida Y, Narao H, Manako Y, Tanaka D, Koga N, Nakano D, Niizeki T, Matsuse H, Torimura T and Shiba N: Slow walking speed overlapped with low handgrip strength in chronic liver disease patients with hepatocellular carcinoma. Hepatol Res 49(12): 14271440, 2019. PMID: 31273895. DOI: 10.1111/hepr.13405

19 Nishikawa H, Shiraki M, Hiramatsu A, Moriya K, Hino K and Nishiguchi S: Japan Society of Hepatology guidelines for sarcopenia in liver disease (1st edition): Recommendation from the working group for creation of sarcopenia assessment criteria. Hepatol Res 46(10): 951-963, 2016. PMID: 27481650. DOI: 10.1111/hepr.12774

20 Arai H, Akishita $M$ and Chen LK: Growing research on sarcopenia in Asia. Geriatr Gerontol Int 14: 1-7, 2014. PMID: 24450555. DOI: $10.1111 /$ ggi.12236

21 Alfonso JC, Gülistan B, Jürgen B, Yves B, Olivier B, Tommy C, Cyrus C, Francesco L, Yves R, Avan AS, Stéphane MS, Cornel CS, Eva T, Maurits V, Marjolein V and Mauro Z, Writing Group for the European Working Group on Sarcopenia in Older People 2 (EWGSOP2) and the Extended Group for EWGSOP2: Sarcopenia: Revised European consensus on definition and diagnosis. Age Ageing 248(1): 16-31, 2019. PMID: 30312372. DOI: 10.1093 /ageing/afy 169 
22 Sinclair M, Gow PJ, Grossmann M and Angus PW: Review article: sarcopenia in cirrhosis--aetiology, implications and potential therapeutic interventions. Aliment Pharmacol Ther 43(7): 765-777, 2016. PMID: 26847265. DOI: 10.1111/apt.13549

23 Lai JC, Covinsky KE, McCulloch CE and Feng S: The liver frailty index improves mortality prediction of the subjective clinician assessment in patients with cirrhosis. Am J Gastroenterol 113(2): 235-242, 2018. PMID: 29231189. DOI: 10.1038/ajg.2017.443

24 Bhanji RA and Montano-Loza AJ and Watt KD: Sarcopenia in Cirrhosis: Looking beyond the skeletal muscle loss to see the systemic disease. Hepatology, 2019. PMID: 31034656. DOI: 10.1002/hep.30686

25 Tur JA and Bibiloni MDM: Anthropometry, body composition and resting energy expenditure in human. Nutrients 11(8): pii: E1891, 2019. PMID: 31416130. DOI: 10.3390/nu11081891

26 Santos DA, Dawson JA, Matias CN, Rocha PM, Cláudia S, Minderico CS, Allison DB, Sardinha LB and Silva AM: Reference values for body composition and anthropometric measurements in athletes. PLoS One 9(5): e97846, 2014. PMID: 24830292. DOI: 10.1371/journal.pone.0097846

27 Utkualp N and Ercan I: Anthropometric measurements usage in medical sciences. Biomed Res Int 2015: 404261, 2015. PMID: 26413519. DOI: $10.1155 / 2015 / 404261$

28 Madden AM and Smith S: Body composition and morphological assessment of nutritional status in adults: a review of anthropometric variables. J Hum Nutr Diet 29(1): 7-25, 2016. PMID: 25420774. DOI: 10.1111/jhn.12278

29 Chen LK, Woo J, Assantachai P, Auyeung TW, Chou MY, Iijima K, Jang HC, Kang L, Kim M, Kim S, Kojima T, Kuzuya M, Lee SY, Lee WJ, Lee Y, Liang CK, Lim JY, Lim WS, Peng LN, Sugimoto K, Tanaka T, Won CW, Yamada M, Zhang T, Akishita M and Arai H: Asian Working Group for Sarcopenia: 2019 Consensus Update on Sarcopenia Diagnosis and Treatment. J Am Med Dir Assoc 21(3): 300-307.e2, 2020. PMID: 32033882. DOI: 10.1016/j.jamda.2019.12.012

30 Kawakami R, Murakami H, Sanada K, Tanaka N, Sawada S, Tabata I, Higuchi M and Miyachi M: Calf circumference as a surrogate marker of muscle mass for diagnosing sarcopenia in Japanese men and women. Geriatr Gerontol Int 15(8): 969-976, 2015. PMID: 25243821. DOI: 10.1111/ggi.12377

31 Mohd Nawi SN, Khow KS, Lim WS and Yu SC: Screening tools for sarcopenia in community-dwellers: a scoping review. Ann Acad Med Singapore 48(7): 201-216, 2019. PMID: 31495866.

32 Hiraoka A, Nagamatsu K, Izumoto H, Yoshino T, Adachi T, Tsuruta M, Aibiki T, Okudaira T, Yamago H, Suga Y, Iwasaki R, Mori K, Miyata H, Tsubouchi E, Ninomiya T, Hirooka M, Abe M, Matsuura B, Hiasa Y and Michitaka K: SARC-F combined with a simple tool for assessment of muscle abnormalities in outpatients with chronic liver disease. Hepatol Res, 2019. PMID: 31830344. DOI: 10.1111/hepr.13469

33 Hiraoka A, Izumoto H, Ueki H, Yoshino T, Aibiki T, Okudaira T, Yamago H, Suga Y, Iwasaki R, Tomida H, Mori K, Miyata H, Tsubouchi E, Kishida M, Ninomiya T, Hirooka M, Abe M, Matsuura B, Hiasa Y and Michitaka K: Easy surveillance of muscle volume decline in chronic liver disease patients using finger-circle (yubi-wakka) test. J Cachexia Sarcopenia Muscle 10(2): 347-354, 2019. PMID: 30793533. DOI: 10.1002/jcsm.12392

34 Fukui H, Saito H, Ueno Y, Uto H, Obara K, Sakaida I, Shibuya A, Seike M, Nagoshi S, Segawa M, Tsubouchi H, Moriwaki H,
Kato A, Hashimoto E, Michitaka K, Murawaki T, Sugano K, Watanabe $\mathrm{M}$ and Shimosegawa T: Evidence-based clinical practice guidelines for liver cirrhosis 2015. J Gastroenterol 51(7): 629-650, 2016. PMID: 27246107. DOI: 10.1007/s00535016-1216-y

35 Lurie Y, Webb M, Cytter-Kuint R, Shteingart S and Lederkremer GZ: Non-invasive diagnosis of liver fibrosis and cirrhosis. World J Gastroenterol 21(41): 11567-11583, 2015. PMID: 26556987. DOI: 10.3748/wjg.v21.i41.11567

36 Zarski JP, Sturm N, Guechot J, Paris A, Zafrani ES, Asselah T, Boisson RC, Bosson JL, Guyader D, Renversez JC, Bronowicki JP, Gelineau MC, Tran A, Trocme C, De Ledinghen V, Lasnier E, Poujol-Robert A, Ziegler F, Bourliere M, Voitot H, Larrey D, Rosenthal-Allieri MA, Fouchard HI, Bailly F, Vaubourdolle M and ANRS HCEP 23 Fibrostar Group: Comparison of nine blood tests and transient elastography for liver fibrosis in chronic hepatitis C: the ANRS HCEP-23 study. J Hepatol 56(1): 55-62, 2012. PMID: 21781944. DOI: 10.1016/j.jhep.2011.05.024

37 Romanelli RG and Stasi C: Recent advancements in diagnosis and therapy of liver cirrhosis. Curr Drug Targets 17(15): 18041817, 2016. PMID: 27296314. DOI: 10.2174/ 1389450117666160613101413

38 Nishikawa H, Enomoto H, Ishii A, Iwata Y, Miyamoto Y, Ishii N, Yuri Y, Takata R, Hasegawa K, Nakano C, Nishimura T, Yoh K, Aizawa N, Sakai Y, Ikeda N, Takashima T, Iijima H and Nishiguchi S: Development of a simple predictive model for decreased skeletal muscle mass in patients with compensated chronic liver disease. Hepatol Res 47(12): 1223-1234, 2017. PMID: 28019060. DOI: 10.1111/hepr.12857

39 Kusaka S, Takahashi T, Hiyama Y, Kusumoto Y, Tsuchiya J and Umeda M: Large calf circumference indicates non-sarcopenia despite body mass. J Phys Ther Sci 29(11): 1925-1928, 2017. PMID: 29200625. DOI: 10.1589/jpts.29.1925

40 Seko Y, Mizuno N, Okishio S, Takahashi A, Kataoka S, Okuda K, Furuta M, Takemura M, Taketani H, Umemura A, Nishikawa $\mathrm{T}$, Yamaguchi $\mathrm{K}$, Moriguchi $\mathrm{M}$ and Itoh $\mathrm{Y}$ : Clinical and pathological features of sarcopenia-related indices in patients with non-alcoholic fatty liver disease. Hepatol Res 49(6): 627636, 2019. PMID: 30716793. DOI: 10.1111/hepr.13321

41 Ida S, Kaneko R and Murata K: SARC-F for Screening of sarcopenia among older adults: a meta-analysis of screening test accuracy. J Am Med Dir Assoc 19(8): 685-689, 2018. PMID: 29778639. DOI: 10.1016/j.jamda.2018.04.001

42 Shiraki M, Nishiguchi S, Saito M, Fukuzawa Y, Mizuta T, Kaibori M, Hanai T, Nishimura K, Shimizu M, Tsurumi H and Moriwaki $\mathrm{H}$ : Nutritional status and quality of life in current patients with liver cirrhosis as assessed in 2007-2011. Hepatol Res 43(2): 106-112, 2013. PMID: 23409849. DOI: 10.1111/ hepr.12004

43 Enomoto H, Ueno Y, Hiasa Y, Nishikawa H, Hige S, Takikawa Y, Taniai M, Ishikawa T, Yasui K, Takaki A, Takaguchi K, Ido A, Kurosaki M, Kanto T, Nishiguchi S and Japan Etiology of Liver Cirrhosis Study Group in the $54^{\text {th }}$ Annual Meeting of JSH: Transition in the etiology of liver cirrhosis in Japan: A nationwide survey. J Gastroenterol 55(3): 353-362, 2020. PMID: 31768801. DOI: 10.1007/s00535-019-01645-y

Received May 28, 2020

Revised June 17, 2020

Accepted June 18, 2020 